\title{
Process Approach to Teaching Writing Applied in Different Teaching Models
}

\author{
Chunling Sun \\ North China Coal Medical University \\ Guoping Feng \\ Number 1 Middle School of Kuai Luan \\ Tangshan 063000, China
}

\begin{abstract}
English writing, as a basic language skill for second language learners, is being paid close attention to. How to achieve better results in English teaching and how to develop students' writing competence remain an arduous task for English teachers. Based on the review of the concerning literature from other researchers as well as a summery of the author's own experimental research, the author of this essay for the first time tries to give definitions of the process approach to writing, make a comparison between product and process approach to teaching writing and accordingly make suggestions about the basic principles of teaching writing with the application of the process approach. With this understanding of the process approach to writing, the author focuses on a discussion about the two classroom teaching models by using the process approach, namely teaching models with minimal control and maximal control to different English level students. Experimental study shows that the subjects were all making significant progress in their writing skill.
\end{abstract}

Keywords: English writing, Process approach, Product approach

\section{Definition of process approach to teaching writing}

Process approach to the teaching of English Writing has been advocated in contrast with the traditional product-oriented method of teaching writing, and has been generally accepted and applied by English teachers in their classroom teaching of English writing, though controversy occurs occasionally among researchers concerning which $\mathrm{P}$ is better, the process approach or the product method.

The controversy occurs mainly because there isn't yet a definite and universally accepted definition for the process approach to writing although some features for the approach have been discussed.. According to Graham Stanley, the process approach treats all writing as a creative act which requires time and positive feedback to be done well. In process writing, the teacher moves away from being someone who sets students a writing topic and receives the finished product for correction without any intervention in the writing process itself. Vanessa Steele defines the process approach as focusing more on the varied classroom activities which promote the development of language use; brainstorming, group discussion, re-writing. Nunan (1991) clearly states that the process approach focuses on the steps involved in creating a piece of work and the process writing allows for the fact that no text can be perfect, but that a writer will get closer to perfection by producing, reflecting on, discussing and reworking successive drafts of a text. Fowler (1989) acknowledges that process writing evolved as a reaction to the product approach, in that it met the need to match the writing processes inherent in writing in one's mother tongue, and consequently allow learners to express themselves better as individuals.

According to these above definitions as well as a summery of my own experimental research, I think that process approach to teaching writing should be a process including several stages, namely prewriting or invention activities (brainstorming, group discussion, assessing ideas,); drafting; seeking feedback from peers or the instructor; revising on the whole-text level ( looking at the overall focus, reconsidering organization, deciding whether there is enough evidence, etc.); followed by revising at the paragraph or sentence level, proofreading, and "publishing" the final text. In essence, process approach to teaching writing focuses on the writing process rather than the final product.

\section{Process Approach Versus Product Approach}

Virtually all current composition theorists make a distinction between process-oriented and product-oriented writing.

James McCrimmon sees it as the difference between writing as a way of knowing (process) and wring as a way of telling( product). Donald Murray sees it as the difference between internal and external revision (revising in order to 
clarify meaning for oneself vs. revising in order to clarify meaning for the reader.) Linda Flower sees it as the difference between writer-based and reader-based prose. Nunan(2001) clearly states how very different this "process" approach is from the traditional product-oriented approach. Whereas the product approach focuses on writing tasks in which the learner imitates, copies and transforms teacher supplied models, the process approach focuses on the steps involved in creating a piece of work. The primary goal of product writing is an error-free coherent text. Process writing allows for the fact that no text can be perfect, but that a writer will get closer to perfection by producing, reflecting on, discussing and reworking successive drafts of a text. Though these theorists differ in their explanations of the distinction between process- and product-oriented writing, there is one important point upon which they all agree: good product depends on good process.

\section{Two classroom teaching models by using process approach:}

Two teaching models are proposed, namely, the full open process teaching of writing, and close process teaching of writing. They are also called teaching models with minimal control and maximal control. This two teaching models are classified in corresponding to students to two different writing levels, including those of good writing skill, those of average writing skill. Students can also be divided into independent, average groups according to their different learning strategies. And in consideration of the students' affective factors, they can be classified into groups of extroversive, and fuzzy types.

\section{Using minimal control teaching model to}

The first group students with good writing skill, extroversive type, independent characteristics

\subsection{Topic: News reports}

\subsection{Aims:}

To develop students' abilities to organize information and construct it into a text.

To develop students' abilities to revise, redraft and improve their writing.

To develop students' abilities to construct questions.

\subsection{Introduction:}

During this lesson students will go through the process of developing ideas and collecting and organizing information. They will then use the information to create the first draft of an imaginary news article. They will then focus on some key areas of good writing and try to redraft their articles with these in mind.

\subsection{Procedure:}

\subsubsection{Pre writing tasks}

Rationale: This part of the lesson should give students the opportunity to collect information before writing the news report. This should reduce the amount of creativity needed during the actual writing.

\subsubsection{Write up the headline:}

Mystery Disappearance of English Woman teacher: Students suspected

1.4.1.2 Put the students in groups or pairs to try to predict the content of the story and what may have happened to the teacher.

1.4.1.3 Get the students to change groups and compare what they think may have happened.

Give out a pile of about 10 to 15 slips of paper. Tell the students to write a question about the story on each slip of paper and give each one to the teacher. (The teacher might want to put up some question words on the board to help promote them. i.e. Who....? What time...? How many...? etc.)

1.4.1.4 As the students give the teacher the slips of paper, the teacher should write very brief answers on them and give them back.

Tip: This works best if the students give each question to the teacher as soon as they write it and

The teacher writes his/her answer on the slip of paper and return it immediately. The answers the teacher gives them will help to prompt them to produce more questions.

If the teacher has a very large class this may not be possible and the teacher may want to stage this over more than one lesson so the teacher has time to write all the replies.

1.4.1.5 Stop when the students have either used up all their slips of paper or run out of questions.

1.4.1.6 Students then collect up the information they have on the slips of paper. Tell them they will use the information to compose a news report to go with the headline. Before they start writing the report it's better to decide what order they will put the information in. 
Tip: A common order for newspaper reports of this kind is:

-headline

-General information about crime

-More details about what happened

-A description of any suspects or the criminals

-What police have done/are doing to try to solve the crime?

- (possible appeal for witnesses)

\subsubsection{Writing Tasks}

1.4.2.1 Once they have grouped the information, tell them to write the report and make sure to include all the information from their questions.

1.4.2.2 Once the students have written their reports, ask them to exchange them with another student and give out the Editor's checklist. The students then use this to check through each other's work and write on any comments or suggestions for improvement.

\section{Editor's checklist:}

Is the information grouped into logical paragraphs?

Are the paragraphs in a logical order?

Is there any unnecessary information?

Are there any parts that you can't understand?

Are a lot of the same words repeated?

Can more precise words be used?

Is there too much repetition of linkers like and, but, then etc?

Do all the verbs agree with their subjects? (e.g. She are/is ....)

Have articles (the, a, an) been used correctly?

Have the correct verb forms been used?

Is the punctuation correct?

Have all the words been spelt correctly?

1.4.2.3 They then give the checked report back to the original writer who makes any corrections or changes and produces a final draft.

Tip: Generally I've found that the process of drafting, adding comments and redrafting works best when done on a word processor as it is much easier for students to make changes to their text without having to rewrite the whole thing.

If your students don't have access to computers then you might consider spreading the redrafting over more than one lesson.

1.4.3. Possible follow up tasks

-Put the reports up on the walls around the class and get the students to look at them all and choose the one they think is best.

Or

-Collect up the students' slips of paper with their questions on and do some error correction work.

Or

Collect some short authentic news articles from either the internet or newspapers and tell the students to compare them with their own:

They should look for:

The way information is organized (how many paragraphs, what is the focus of each paragraph?)

The verb forms or structures used (present perfect, present simple, active or passive)

Ways in which the writer has made the writing more exciting (use of adverb, adjectives, variety of lexis)

Or

Give the students the following headline: 


\section{Mystery of the Disappearing Women Teacher Solved}

Ask them to produce a report for the radio or TV on how the mystery was solved and what happened. They could even include interviews with the teacher and students involved. ( The teacher could record this or video it if he/she has access to a camera. )

\section{Using maximal control teaching model to}

The second group students with average writing skill and learning strategies, fuzzy characteristics

2.1 Topic : Why People Take Drugs

\subsection{Aims:}

-To develop students' abilities to organize information and construct it into a text.

-To develop students' abilities to revise, redraft and improve their writing.

-To develop students' abilities to construct questions.

\subsection{Procedure}

\subsubsection{Prewriting tasks:}

2.3.1.1 Rationale: In this part of the lesson, the teacher needs to stimulate students' creativity, to get them think how to approach a writing topic. In this stage, the most important thing is the flow of ideas, and it is not always necessary that students actually produce more (if any) written work. If they do, then the teacher can contribute with advice on how to improve their initial ideas.

\subsubsection{Write up the headline}

\section{Why People Take Drugs?}

Tribble (1996) states that assigning tasks that pose real problems to the learner will keep their motivation high and create a sense of achievement. I have found this to be true in my own experience, and that by engaging learners in something that i) they are interested in, and ii) they can give positive input to, can create a truly active and interactive writing environment.

\subsubsection{Group brainstorming on the given topic (Why people take drugs?)}

As is well-known, getting started can be difficult, so students divided into groups quickly, work cooperatively and write down all the ideas that come to mind in connection with the given topic. According to my teaching experience, as little as 5 minutes can be effective.

Brainstorming involves thinking quickly and without inhibition, which can ultimately lead to an interesting piece of writing.

The teacher should remain in the background during this phase, only supplying language support when students need it, so as not to inhibit students in the production of their ideas.

-Evaluating ideas during brainstorming can be intimidating, and can have a negative effect, limiting the creativity the process is designed to promote.

\subsubsection{Assessing ideas}

Students are encouraged to extend their ideas into a mind map, spidergram or linear form.

It is in this stage that students can judge the quality and usefulness of their ideas.

A mind map or spidergram is also an organized display of information, which can be more easily converted into a draft. such graphics also make the (hierarchical) relationship of ideas more easily obvious, which will help students with the structure of their texts.

\subsubsection{A model text:}

To the lower level students in English, I think it is better to combine the process- and product-oriented approach to teaching writing. Of course, I believe that it is of great importance from the process-oriented approach to perform the above discussion stages in writing. Next, I tend to introduce a model text.

The reading of a model text, so important in a product-oriented approach to writing, is not so as to subjugate the students' ideas to their organization, but so as to make students aware that there is a particular way to express their ideas. In this way, students are given the form in order to enable them to adapt it to carry their own meaning. Ellis found evidence to suggest that "focusing learners' attention on forms, and the meaning they realize the context of communication activities, results in successful language learning."

Focus on model text coherence 
Coherence refers to the logical development of ideas within a text and it is an important subskill for students to be aware of. The teacher can highlight this in various ways, by focusing on the topic and function of each paragraph for example, or by examining how the writer has chosen to order his arguments. This focus will hopefully show students that if they are to convey their message successfully, they will have to make their text "reader friendly".

Cohesion

Cohesion refers to the grammatical and lexical connections between individual clauses. The grammatical links can be classified under three broad types:

- Referents (pronouns, the article "the", demonstratives)

- Ellipsis (leaving out of a words or phrases where they are unnecessary)

- Conjunction (a word which joins phrases or clauses together)

Pronouns, whether subject(he), object(him), possessive(his), relative(who), or reflexive(himself), are often underused or misused by students while performing a writing task, resulting in either confusion as to the reference or tedious repetition of a noun.

One way of raising awareness of the key function that pronouns play within a text is to ask students to circle all the pronouns, then to use arrows to connect them to their referent. This shows students that pronouns can be found by looking back or forwards in the text.

There are many other activities that can be used to focus on cohesion. For example, asking students to replace a sentence which is missing from each paragraph, or to replace the first sentence of each paragraph, matching clauses which have been separated or gapping conjunctions which students must replace from a selection.

\subsubsection{Questioning :}

In the process of group discussion, there must generate lots of questions about the topic. The teacher should try his/her best to give proper answers immediately which can help students focus upon audience as they consider what the reader needs to know. The answers to these questions will form the basis to the composition. At the same time, the teacher had better provide more guidance in student's developing ideas in a positive and encouraging way.

All of the above activities work best if carried out in groups as groupings make the tasks livelier and more enjoyable. Moreover, if students can work together, assisting each other, then the atmosphere of the writing class may be less intimidating, and perhaps students will not be afraid of the complexity of writing tasks.

\subsubsection{Writing Production}

This stage involves the learners in writing the first draft of their texts with a partner. This pair work will help students see that writing really is co-operative, a relationship between writer and reader. Usually, the writer has to imagine a reader, but co-operative writing provides each writer with a reader and makes the task more realistic and interactive.

\subsubsection{Fast and collaborative writing:}

The students write quickly on a topic for five or ten minutes without worrying about correct language or punctuation. Writing as quickly as possible, if they can't think of a word, they leave a space or write it in their own language. The important thing is to keep writing. Later this text is revised. At the same time, I find collaborative writing can be quite motivating. It enables the stronger students to help the weaker ones.

\subsubsection{Whole class text construction, composing on the blackboard and parallel writing}

These techniques have their foundation in product writing but are effective in providing a framework for lower level students to work from. These techniques can develop a sense of collective achievement, while eliminating the fear of being left to "go it alone", completely unguided.

\subsubsection{Students consult each other and co-construct texts}

During such an activity, the teacher should move around listening to their comments, providing feedback or answering questions on structure, lexical items, the validity of an argument, the order of presentation of the information, etc. therefore, I can keep track of their progress and work out a record of most frequent questions, doubts and inaccuracies for a future's error analysis' session.

\subsubsection{Revision}

\section{- $\quad$ Self-editing}

A good writer must learn how to evaluate their own language, how to improve through checking their own text, looking for errors. This way students will become better writers.

- $\quad$ Peer Editing 
Students exchange their first drafts of a text and point out changes which are needed to help the reader(e.g. better organization, paragraph divisions, sentence variety, vocabulary choice). They can also act as each other's editors (spotting vocabulary repetitions, grammatical errors, spelling mistakes, etc). At the same time, students are required to provide written feedback to the student authors.

Peer editing is a useful tool for any level of learner, for example, to the intermediate level students, this can be used to assess how effectively an essay question has been answered.

- Whole class discussion of how a particular text might need adjustment according to the audience it is addressed to.

One technique I regularly employ is to ask my students to imagine that I am a small child, and to explain what they consider to be a straightforward topic (for example, Why People Take Drugs?) in words that a child would understand. I then ask them to explain the same topic to me, only this time they imagine I am a university professor, and ask them to adjust their language appropriately.

\section{- Evaluation:}

It takes a lot of time and efforts to write, and so it is only fair that student writing is responded to suitably. Positive comments can help build student confidence and create good feeling for the next writing class. Through my experience I've found that evaluation is most useful if it is given on the basis of what the learner has asked for. In my experience, learners still favor comments on the grammatical and lexical correctness of their work. In order to make this interactive activity, I use an error correction code, which serves to highlight the error but still requires the learners to reflect on what the error actually is. Sometimes I use some questions like "What do you mean here?" or, "Can you tell me more about this?".

\section{- $\quad$ Final draft}

Drafts are returned and improvement are made based upon peer feedback. Then the final draft is written. In addition, students can also exchange and read each others' work and perhaps even write a response or reply.

\section{Conclusion}

Experimental study shows that the two groups of students who received two different models of teaching writing were all making significant progress in their writing skill, while the control groups who as a whole class received full open process model of teaching made less progress in their writing skill except for some good students who scored almost as high.

It is concluded that the process approach to teaching writing can be and is ideally applied in different teaching models, and when we use the same process approach but different models of teaching writing to teach the different students, an optimal teaching effect can be realized.

\section{References}

Caifang Kong. (2005). Review on the Writing Theories of Foreign language in China. Foreign Languages' Teaching and Research.

Flower, L. (1985). Problem-solving strategies for writing. Second Edition. San Diego, Harcourt: Brace Jovanich.

Fowler W.S. (1989). Progressive Writing Skills. Surry: Thomas Nelson and Sons Ltd.

Graham Stanley. (1993). Process Writing, British Council, Barcelona.

James McCrimmon, (1994). Writing with a Purpose. Houghton Mifflin co.

Lanzhen Cai. (2001). Application of Product Teaching on College English Writing. Journal of the Foreign Language World.

Liming Deng. (2003). Hints of Systematic Research of Process Teaching to College English Teaching. Foreign Language Teaching.

Murray, D. (1980). Writing as Process: How Writing Finds its Own Meaning. In T.R. Donovan and B.W.MecClelland(eds), English Approach in Teaching Writing.

Nunan, David. (1991). Language Teaching Methodology. A Textbook for Teachers. Prentice Hall.

Nunan, David. (2001). Second English Teaching and Learning. Beijing: Foreign Language Teaching and Research Press.

Tribble, C. Writing. (1996). Oxford: Oxford University Press.

Vanessa Steele. (1992). Product and Process Writing: A Comparison. Rowley: Newbury House.

Xinying Hu. (2003). Application of Process Teaching. Journal of the Foreign Language World. 